\title{
Perforator Flap: A Changing Paradigm for The Reconstructive Plastic Surgery in Bangladesh
}

\author{
T AHMED ${ }^{\mathrm{a}}$, MA KALAM ${ }^{\mathrm{b}}$
}

In recent years, the use of perforator flaps in reconstructive surgery, which is based on their blood supply specifically on subcutaneous tissue and or specific perforators, has become increasingly popular ${ }^{1}$. A few years back, Plastic and Reconstructive Surgeons were fascinated by the ability to harvest skin and adipofascial flap, along with the underlying tissue or muscle. The latter was considered an essential source of vascular supply at that time ${ }^{2,3}$. However, the strategy to reduce donor site morbidity has driven the surgeons towards game-changing perforator flaps. Which in turn facilitates the harvest of cutaneous and adipofascial tissue without the necessity to include underlying tissue or muscle ${ }^{4}$. The perforator flap can be modified to harvest as a local flap or free flap but for a better resurfacing and extend of use it can be rotated which is called a 'Propeller Flap'2,5.

A propeller flap can be defined as an "island flap that reaches the recipient site through an axial rotation." The classification is mainly based on the source of the pedicle (subcutaneous pedicled propeller flap, perforator pedicled propeller flap, supercharged propeller flap), the degrees of skin island rotation (90 to 180 degrees), and the arterial origin of the perforator $^{2,5-7}$. A flap should be termed as a propeller flap only if it fulfills the above descriptions. The type of pedicle, the source vessel (when known), and the degree of skin island rotation should be specified for each flap ${ }^{4}$.

The German medical student Carl Manchot usually be cited [1889] for his thesis on cadaver dissections explored that the "larger cutaneous arteries appear from the fissure between muscles directly above the fascia, they are divided into terminal branches and interconnected". But in that time, he did not name them as perforators ${ }^{2,5,8}$. The term "perforator" was specifically used for the first time by Kroll and
Rosenfield in 1988 in the title of a journal article, where they had described uniquely the local perforator flaps for posterior midline defects. Koshima, considered as the "father" of perforator flaps, in 1989 published the use of periumbilical flaps based on deep inferior epigastric artery perforators. Hyakusoku coined the term propeller flap in $1991^{2,5}$. Again in 1998, Koshima became a superstar for introducing the super-microsurgery concept showing the ability to anastomose the perforator-to-perforator vessels successfully. Blondeel, whose continued and extraordinary zealousness had named him "Mr. Perforator Flap," combined with his colleagues he wrote the first book on just perforator flaps, published in $2006^{2,5,9}$.

The deep inferior epigastric artery perforator flap (DIEAP) and anterolateral thigh flap (ALT) by far remain the perforator flaps most commonly selected. Breast reconstruction using not only deep inferior epigastric artery perforator flaps, but also gluteal, superficial inferior epigastric, or intercostal artery perforators appeared to be the most common subject. Although originally most often considered as free flaps, these same perforators are now being used more and more as the basis of local flaps, and in particular as propeller flaps ${ }^{8,10}$.

In many instances, it has become very unusual today to open any reconstructive surgery journal and not find at least one article including the keyword "perforator." The numbers do not lie - perforator flaps prove their universal acceptance as an important reconstructive tool and as a distinct identity that has a place that is here to $\operatorname{stay}^{2,9}$.

In Bangladesh, due to the availability of resources, Plastic Surgeons are performing perforator-based flaps very regularly. It saves time and money when considered for trauma and cancer reconstructions. Now the Plastic Surgeons are leading the 
perforator-based DIEAP free flap for breast reconstructions and ALT free flap for other complex reconstructions in the country. In the bottom line, the propeller flap is a useful reconstructive tool that can achieve good aesthetic and functional outcomes.

(J Bangladesh Coll Phys Surg 2021; 39: 78-79)

DOI: https://doi.org/10.3329/jbcps.v39i2.52385

a. Dr. Tanveer Ahmed, Associate Professor, Sheikh Hasina National Institute of Burn and Plastic Surgery, Dhaka, Bangladesh. Email: tahimon@gmail.com

b. Prof. Md. Abul Kalam, Professor and Director, Sheikh Hasina National Institute of Burn and Plastic Surgery, Dhaka, Bangladesh. Email: kalammishu@yahoo.com

\section{References:}

1. Pignatti M, Ogawa R, Hallock GG, et al.. The "Tokyo" consensus on propeller flaps. Plast Reconstr Surg. 2011;127:716-722.

2. Hallock GG. A brief history of perforator flaps. J Xiangya Med. 2018;3:4-10.

3. Blondeel Ph.N., Van Landuyt K., Hamdi M., Monstrey S.J. Perforator flap terminology: update 2002. Clin Plastic Surg. 2003; 30:343-346.
4. Taylor G.I. The angiosomes of the body and their supply to perforator flaps. Clin Plastic Surg. 2003; 30:331-342.

5. Hallock GG. If based on citation volume, perforator flaps have landed mainstream. Plast Reconstr Surg 2012;130:769e-71e.

6. Saint-Cyr M, Wong C, Schaverien M, et al. The perforasome theory: vascular anatomy and clinical applications. Plast Reconstr Surg 2009;124:1529-1544.

7. Koshima I., Nanba Y., Tsutsui T., Takahashi Y. Medial plantar perforator flaps with supermicrosurgery. Clin Plastic Surg. 2003; 30:447-455.

8. Mardini S., Tsai F.C., Wei F.C. The thigh as model for free style free flaps. Clin Plastic Surg. 2003; $30: 473-480$

9. Hallock GG. Direct and indirect perforator flaps: The history and the controversy. Plast Reconstr Surg. 2003;111:855-865.

10. londeel PN, Morris SF, Hallock GG, et al. Editors. Perforator Flaps: Anatomy, Technique, \& Clinical Applications. St. Louis: Quality Medical Publishing, 2006. 